\title{
Attitude Change in Computer-Mediated Communication: Effects of Anonymity and Category Norms
}

\author{
Kai Sassenberg \\ Friedrich-Schiller University of Jena \\ Margarete Boos \\ Georg-August University of Göttingen
}

\begin{abstract}
The current research compared the effect of computer-mediated communication (CMC) and direct communication on attitude change. The social identity model of deindividuation effects (Spears \& Lea, 1994) predicts that CMC results in behavior that is more in line with the salient level of self-categorization (compared to non-anonymous communication): in CMC salient social identity should lead to conformity to group norms whereas salient personal identity was expected to result in behavior that fits individual goals. Two experiments showed that when personal identity was salient and when social identity was salient and a category norm was explicitly given, CMC led to the predicted effects, whereas the lack of a social category norm led to lower attitude change in $\mathrm{CMC}$ compared to direct communication.
\end{abstract}

KEYWORDS anonymity, computer-mediated communication, group norms, social influence

WITH THE growing number of Internet users a new media for interpersonal and mass communication becomes more and more a part of everyday life. Computer-mediated communication (CMC) has various effects on communication itself as well as on its outcomes (for a summary see McKenna \& Bargh, 2000). Because research on CMC is still comparatively infrequent, predictions of the impact of CMC have only been tested in some fields. Studies comparing attitude change within groups using face to face (FTF) and CMC produced inconsistent results: in some studies attitude change in FTF groups was higher than in groups

\footnotetext{
Author's note

The studies reported in this article were conducted while Kai Sassenberg was still at the Georg-August University.

Address correspondence to Kai Sassenberg, Department of Social Psychology, Humboldtstrasse 26, D-07743 Jena, Germany, [email: kai.sassenberg@uni-jena.de]
} 
using CMC (e.g. McGuire, Kiesler, \& Siegel, 1987). Conversely, in other studies the reversed pattern of results was found (e.g. Kiesler, Siegel, \& McGuire, 1984). According to the Social Identity Model of Deindividuation Effects (SIDE; Reicher, Spears, \& Postmes, 1995; Spears \& Lea, 1994) these findings (a) can be explained as an effect of higher anonymity in CMC compared to FTF communication and (b) this effect of anonymity is moderated by the level of salient identity. When social identity is salient, anonymity fosters social influence; thus, attitude change is expected to be higher in CMC compared to FTF communication. However, when personal identity is salient, anonymity hinders social influence within groups. Therefore, with personal identity being salient one would expect less attitude change in FTF than in CMC. The aim of the current research is to test this explanation of the inconsistent findings with studies comparing attitude change in groups employing FTF and CMC. At the same time, the current research examines whether the SIDE's predictions about the impact of anonymity can be generalized to the comparison between FTF and CMC.

\section{Social influence in CMC}

One of the first models developed to explain the effects of CMC was the reduced social cues approach (RSC; Kiesler et al., 1984; Kiesler \& Sproull, 1992) which addresses the effects of communication media on social influence within groups. The central assumption of the RSC approach is that in groups using CMC less social contextual information is available and therefore behavior is less strongly oriented toward societal norms than in FTF groups. Moreover, Kiesler et al. (1984) argue that CMC embodies some conditions that are also part of the deindividuation concept: anonymity, lower self-awareness, and reduced self-regulation. In a state of deindividuation people show more extreme behavior (i.e. behavior deviating from norms) after being submerged in a crowd (Festinger, Pepitone, \& Newcomb, 1952). Thus, the central assumptions of the RSC approach parallel deindividuation theory (Diener, 1980): fewer social contextual cues as well as anonymity in crowds lower self-awareness. Resulting from reduced self-awareness, behavior is predicted to become deregulated, more extreme, and less guided by societal norms. Less inhibited behavior leads, according to the assumptions of Kiesler et al. (1984), to more extreme group decisions and a stronger shift of group members' attitudes during a discussion in CMC: 'If [...] extreme opinions are less likely to be withheld (because behavior is less inhibited), then we would predict more choice shift in computer-mediated groups' (Kiesler et al., 1984, p. 1128). Thus, more polarized attitudes become more likely after a computermediated than after an FTF discussion. This brief summary does not capture the whole complexity of the RSC approach. However, it might give an impression of the numerous concepts that were taken into account (for a more extensive summary and critique of the RSC approach see Lea \& Spears, 1991; Spears \& Lea, 1992).

Studies testing the RSC approach (Kiesler et al., 1984; McGuire et al., 1987; Siegel, Dubrovsky, Kiesler, \& McGuire, 1986; Weisband, 1992) usually compared groups communicating FTF with groups using CMC. The dependent measure was the attitude change from the individual decision before the group discussion either to the group decision or to the individual decision after the discussion. The prediction that more attitude change would occur in CMC was not always confirmed. McGuire et al. (1987) found less attitude change and less extreme decisions in CMC groups than in FTF groups and Weisband (1992) observed no differences. However, Siegel et al. (1986) and Kiesler et al. (1984) found larger choice shifts in computermediated groups than in FTF groups. Additionally, the RSC approach is questioned by several studies demonstrating that self-awareness is not lower in CMC, as expected from the model, but higher than in direct communication (Matheson \& Zanna, 1988, 1989; Sassenberg, Rabung, \& Boos, 1999). Taken together, the RSC approach is not able to explain these contradictory results. Hence, there is a need for a 
theoretical approach that can predict attitude change in different communication media.

A comparatively simple explanation for the contradictory findings concerning the effects of media type on attitude change has been provided by SIDE (Spears \& Lea, 1992). SIDE builds on social identity theory (SIT; Tajfel \& Turner, 1979) and self-categorization theory (SCT; Turner, Hogg, Oakes, Reicher, \& Wetherell, 1987). Both theories suggest that the self-concept is made up by one's individuality as well as by one's group memberships (e.g. gender, school, sports team). The relevance of these different aspects of the self depends on the respective social context. When personal identity is salient (i.e. self perception is dominated by individual characteristics) the behavior will be guided by personal goals, such as the need to show individual distinctiveness. However, when a social identity is salient (i.e. self-perception is dominated by the membership of a group) the behavior will be guided by the norms of the respective group. The duality of behavioral consequences as a function of the level of salient identity may also be applied to social influence within groups. When social identity is salient attitude change after a group discussion is expected to be oriented toward the group norm. In ad hoc groups the norm corresponds to the prototype of the group, defined as attitude that differs least from the ingroup members' attitudes and the most from the outgroup members' attitudes. In case the context does not allow a comparison to an outgroup (e.g. when an interacting group is making a decision in the absence of any other group) the range of possible attitudes (i.e. the scale positions which are not held by ingroup members) replaces the outgroup as comparison standard (Turner, 1991). When personal identity is salient, predictions for attitude change are less clear: the need for individual distinctiveness can either be fulfilled by shifting one's attitude away from others' attitudes (i.e. the group norm) or by showing an attitude that promotes one's personal identity (e.g. when changing one's expectations or values leads to success in meeting one's own standards and makes one feel better). In sum, SCT explains group polarization neither by exchange of arguments (Vinokur \& Burnstein, 1974), nor by normative pressure (Goethals \& Zanna, 1979), but instead as an effect of the self-definition as a group member which in turn leads to the intrinsic adherence to the group norm. This norm is either learned in earlier interactions or, in the case of an interacting group, it is the group prototype which is inferred from the individual attitudes.

Taken together, SIT and SCT provide a framework for the explanation of social influence (beside other group phenomena) and allow predictions of attitude change in two directions. When social identity is salient attitudes should shift toward the group norm (i.e. the given tendency within a group). Conversely, when personal identity is salient attitudes should shift away from the group norm (allowing individuals to display individual distinctiveness from group norms) or toward a self-serving position. SIDE extends SIT and SCT with respect to the effect of anonymity on group processes. Reicher $(1984,1987)$ first proposed an explanation for the effect of anonymity on behavior in crowds based on SIT/SCT. He suggested that people in anonymous crowds have an enhanced social identity. Therefore, in such situations people act closely in line with the norm of their own group. It should be recognized that this norm differs from general societal norms addressed in earlier deindividuation theory (Diener, 1980). Extending this assumption, SIDE (Reicher et al., 1995) provided a more detailed analysis of the effects of anonymity. When social identity is salient, anonymity leads to a homogeneous perception of the ingroup, as anonymity hinders the perception of possible intragroup differences. In anonymous groups the social categorization becomes even more salient and group members show higher conformity to the ingroup norm. When personal identity is salient, anonymity limits information concerning interindividual similarities. Hence, there is no basis for the development of a common social identity. As a consequence, behavior promoting the uniqueness of the person as an individual will be more likely in an anonymous as opposed 
to a non-anonymous group. Several findings support SIDE (for an overview see Postmes \& Spears, 1998; Postmes, Spears, \& Lea, 1999; Postmes, Spears, Lea, \& Reicher, 2000).

Anonymity, the situational feature addressed in SIDE, is one of the characteristics with a strong impact on social psychological phenomena in which CMC differs from FTF communication (McKenna \& Bargh, 2000). Thus, the predictions of SIDE may reconcile the seemingly contradictory findings of studies showing more attitude change in groups using CMC on the one hand (Kiesler et al., 1984; Siegel et al., 1986) and studies showing less attitude change in CMC on the other hand (McGuire et al., 1987). The former would be expected, according to SIDE, when social identity is salient, ${ }^{1}$ the latter when personal identity is salient. Even studies showing no differences in attitude change between both communication media (e.g. Weisband, 1992) can be integrated in this framework. When neither a personal nor a common social identity is clearly salient, anonymity should not affect the amount of attitude change. Even though the results from studies comparing attitude change in FTF and CMC can be explained based on SIDE, two questions remain.

First, in most research on social influence related to SIDE (e.g. Spears, Lea, \& Lee, 1990; Lea \& Spears, 1991; for an overview see Postmes et al., 2000) the degree of anonymity within CMC rather than the communication media was varied. The question yet unanswered is whether a broader manipulation of anonymity, like the comparison between FTF and CMC, will also lead to the effects predicted by SIDE. This, however, is necessary to conclude that the inconsistent results of studies comparing attitude change in groups using FTF or CMC are due to the level of salient identity in the specific experimental setting.

Second, and theoretically more important, there is another clear difference between studies on SIDE and studies comparing attitude change after CMC and FTF discussions. In almost all experiments that supported the predictions of SIDE, participants were provided with information about the group norm. Spears et al. (1990) informed the participating first year psychology students explicitly about the attitudes of last year's freshmen. In other studies the norm was induced by a priming procedure (Postmes, Spears, Sakhel, \& de Groot, 2001) or an initial group task (Postmes \& Spears, 1997). In the studies that tested the RSC approach, neither the norm of the small group nor the norm of a social category that is superordinate to the interacting small group (superordinate social category) was explicitly given. Waldzus and Schubert (2000, Experiments 1-3) recently addressed the impact of imposing a category norm because they did not succeed in replicating the effect predicted by SIDE in a series of studies. In these web experiments either participants' personal identity or the social identity of a virtual group was salient. Participants were informed about the attitude of the members of their virtual group who were at the same time members of a common social category. The four group members were either anonymous or non-anonymous. Differing from earlier research on SIDE, no interaction between group members was possible. In all three experiments results contradicted SIDE. When social identity was salient, attitude change was lower in the anonymous condition, whereas when personal identity was salient, attitude change was higher in the non-anonymous condition. In an additional experiment, Waldzus and Schubert (2000, Experiment 4) tested the moderating impact of the fit between the norm of the local group and the norm of the social category. Participants were informed about the attitudes of the members of their virtual group and the norm of a shared social category. In all conditions the social identity based on the shared common social category was rendered salient. Members of the virtual group were either anonymous or non-anonymous. For half of the items the norm of the local group and the social category were similar, whereas the two norms differed for the rest of the items. As predicted by Waldzus and Schubert, participants in the anonymous condition showed more attitude change than participants in the non-anonymous condition 
(i.e. behaved in line with the predictions of SIDE) only when there was a fit between the norm of the social category and the virtual group. No effect of anonymity on attitude change was found when both norms differed. In sum, these experiments indicate that providing participants with a reference norm is a precondition for the effects of anonymity predicted by SIDE (at least) when participants do not interact with their local group. However, it is not clear yet whether this is also true for interacting groups.

\section{Overview of the current research}

The aim of the current research was to test whether the inconsistent findings from studies comparing the attitude change in groups communicating (non-anonymously) FTF and (anonymously) computer-mediated can be attributed to the moderating effect of the salient level of identity. In Experiment 1 the effect of a broader manipulation of anonymity (FTF vs. CMC) on attitude change within groups, with members having a salient personal vs. a salient social identity, was tested. Experiment 2 addressed the second question mentioned above. Is providing participants with the norm of a superordinate social category also a necessary precondition for the predictions made by SIDE when interaction within the group takes place? In other words, the moderating role of imposing a norm of the superordinate social category was tested.

\section{Experiment 1}

In a $2 \times 2$ between-subjects design we varied the communication media and the level of selfcategorization. As this experiment tested whether the inconsistent results of the studies on comparison of social influence between FTF and CMC can be explained by an effect of salient personal vs. social identity, the procedure followed as closely as possible the studies on media comparison referred to above. Groups of three participants either communicated FTF or via synchronous text-based CMC. Before the interaction took place, either personal identity or social identity was made salient. No reference norm was given or experimentally induced, because studies on media comparison had not given a reference norm either and SIDE does not state that giving a reference norm is a necessary condition within the model. Following SCT, the prototype of the interacting group may also serve as a norm. Turner (1991) argued that in a setting without an explicit outgroup, group members perceive the scale positions which are not occupied by the ingroup members as possible outgroup opinions.

The overall direction of attitude change was predicted following the explanation of group polarization within the framework of SCT (e.g. Turner, 1991; Wetherell, 1987): When social identity is salient, the attitude change was expected to be oriented more toward the group norm than when personal identity is salient, regardless of the communication media used. Moreover, following SIDE it was predicted that this effect would be even stronger in the CMC condition than in the FTF condition. The salient of a social identity was expected to lead to more adherence to the group norm after CMC than after FTF communication. Personal identity was thought to release behavior being more in line with participants' personal goals and deviating from the group norm in CMC compared to FTF communication. In contrast to SIDE, the RSC approach would predict a stronger attitude change away from societal norms in the CMC than in the FTF condition, no matter which identity category was salient.

\section{Method}

Design and sample To test these predictions, an experiment with the two independent variables communication media (CMC vs. FTF) and salient level of identity (personal vs. social identity) was run. Seventy-two students (47 females and 25 males) from the University of Göttingen (Germany) took part in experimental groups of three. One group had to be omitted from the analysis because one participant prematurely left the laboratory. The students' mean age was 23 years (range 18-29). 
Participation was voluntary and the participants received no financial compensation.

Procedure The groups were randomly assigned to one of the four experimental conditions. After the arrival of all three participants, they were requested to give a judgment in terms of percentage in a moral dilemma which was adapted from Kohlberg's medicine dilemma (German version: Hinder, 1987):

Your partner is terminally ill. All the treatment methods have failed. A new medicine against this illness has just been developed. The doctors believe it could save your partner. You know that this medication is your partner's last hope, you would like to buy it. However, even if you go into debt the medicine is too expensive for you to pay for. Attempts to bargain over price or to pay in installments were unsuccessful. Your only hope of getting the medication is to steal it and in doing so to risk getting arrested.

How large would your partner's recovery chance due to the medication have to be (in \%) for you to risk breaking into the pharmacy?

The answer was measured on a rating scale ranging from $0 \%$ for 'no chance for recovery' to $100 \%$ for 'recovery guaranteed'. The readiness to break the law even though there is only a low chance for the partner to recover would indicate the intention to show anti-normative behavior. One might object that this scenario is not suitable to measure anti-normative behavior because it has been developed to measure moral development. However, it includes at least one central element of societal norms: the law. Thus, this item better addresses the RSC approach's prediction that CMC groups tend to show more anti-normative behavior than FTF groups than earlier items that were mostly based on political attitudes and risky/cautious behavior.

After the participants made a decision, they were requested to discuss the same dilemma in groups of three, either FTF or via CMC, and to reach a decision. After the discussion, participants were again asked to indicate their individual opinion concerning the dilemma and to fill in a demographic questionnaire. Finally, the participants were debriefed and thanked.
Experimental manipulations To vary the communication media FTF and CMC were used. Directly upon arrival participants in the CMC condition were led to separate rooms equipped with PCs to avoid any contact between the members of a group. Participants were instructed how to use the CMC software. Messages were visible on the screens of the other group members less than 0.5 seconds after they were sent. Messages scrolled off the screen as soon as the window was full and a new message arrived. The messages were marked only with numbers assigned to the participants in order to maintain anonymity while at the same time allowing participants to follow the discussion in terms of who said what. The participants were informed that the interaction would be recorded. ${ }^{2}$ In every other way the procedure followed the description given above.

In the FTF condition participants gave their first rating at separate desks in the same room. During the group discussion they were placed around a table. The FTF discussions were recorded on video. In order to match the discussions for the different amount of time required to write and read in comparison to speaking and listening, a maximum discussion time of 7: 30 minutes was given in the FTF condition, whereas in the CMC condition discussions lasted a maximum of 30 minutes (Kiesler \& Sproull, 1992).

Salient level of identity was manipulated by different instructions given directly before the discussion. In the personal identity condition the differing individual characteristics were stressed. Participants received an individual code number and they were asked to discuss the medication dilemma with two students majoring in other subjects. In the social identity condition the groups were given group names and were told that they all had the same major. In order to facilitate this instruction in the FTF condition, special care was taken to ensure that the members of a group did not know one another.

Dependent measure The measure of attitude change was attitude change in the direction of the group norm. As the mean scale position 
preferred by the participants before the discussion was $40.97 \%$, i.e. lower than $50 \%$, it was assumed that the group norm was to steal for one's partner. Thus, attitude change toward a lower percentage was computed (i.e. attitude change $=$ attitude before decision - attitude after decision). This procedure is in line with the procedure suggested by SCT as well as by earlier research on group polarization. Higher values indicate more adherence to the group norm and simultaneously attitude change away from the societal norm (i.e. behaving in line with the law).

\section{Results}

To test the hypotheses an analysis of covariance (ANCOVA) with the independent factors communication media and salient level of identity and the opinion prior to discussion as a covariate was computed. ${ }^{3}$ The individual opinion before the discussion covaried with the degree of attitude change $(F(1,64)=24.91, p<.001)$.

It was predicted from SIDE that CMC compared to FTF discussions would result in more attitude change toward the group norm when social identity was salient and a stronger striving for individual distinctiveness when personal identity was salient. A media $\times$ salient level of identity interaction was found $(F(1,64)$ $=11.73, p=.001)$. Contrary to the hypotheses, when social identity was salient more attitude change toward the group norm took place in groups communicating FTF $(M=20.89, S E=$ 4.46) than in groups using $\mathrm{CMC}(M=3.28, S E$ = 4.86) $(F(1,63)=7.25, p=.009)$. Conversely, when personal identity was salient there was stronger polarization in the $\mathrm{CMC}$ condition $(M$ $=17.86, S E=4.44)$ than in FTF communication $(M=4.30, S E=4.43)(F(1,63)=4.66, p=.035)$ (see Table 1).
Overall, the expected main effect for the salient level of identity did not occur $(F(1,64)=$ $.05)$. In the FTF condition attitude change was in line with SIT/SCT: higher when social identity was salient than when personal identity was salient $(F(1,63)=7.26, p=.009)$. In the CMC condition the opposite effect occurred $(F(1,63)=4.92, p=.030)$. Finally, in following the RSC approach, the main effect of the communication condition was not reliable $(F(1,64)$ $=.20)$.

\section{Discussion}

The present study examined whether a broader manipulation of anonymity leads to the pattern of attitude change predicted by SIDE. It was expected that CMC, in being more anonymous than FTF communication, fosters the orientation toward the ingroup norm when social identity is salient, while strengthening the striving for individual distinctiveness when personal identity is salient. Additionally, as predicted by SCT, salient social identity was expected to result in more conformity to the group norm than personal identity. These predictions were only partially confirmed. In the FTF condition, group polarization was greater when social identity was salient than when personal identity was salient. This pattern is in line with the predictions of SCT. In CMC, attitude change showed the reversed pattern instead of the same pattern in a more extreme fashion (as predicted by SIDE). In fact, the influence of social categorization disappeared in CMC. In the personal identity/CMC condition attitude change occurred. Participants were more willing to steal the medicine for their partner after the discussion than prior to it. This attitude change was directed toward the group norm. This is an unexpected finding, because

Table 1. Estimated marginal means and standard errors for attitude change within ANCOVA (communication media $\times$ level of salient identity, covariate decision before discussion $)(N=69)$

\begin{tabular}{lrrrrr}
\hline & \multicolumn{2}{c}{ FTF } & & \multicolumn{2}{c}{ CMC } \\
\cline { 2 - 3 } \cline { 5 - 6 } & \multicolumn{1}{c}{$M$} & & & \multicolumn{1}{c}{$M$} & $S E$ \\
\hline Social identity & 20.89 & & & 3.28 & 4.86 \\
Personal identity & 4.30 & 4.44 & & 17.86 & 4.44 \\
\hline
\end{tabular}


salient personal identity was predicted to cause attitudes that contradict the interacting group's norm. ${ }^{4}$ However, as the participants in this condition were more willing to break the law for their partner after than prior to the discussion, this shift can also be interpreted as showing an intention that corresponds with the individual goal to care for one's partner. Therefore, this finding indicates a stronger fulfillment of personal needs in the CMC than in the FTF condition and confirms the predictions of SIDE. Taken together, the findings in the personal identity condition were unexpected on the one hand, because higher anonymity brings about more conformity to the group norm. On the other hand, they were in line with the predictions of SIDE, because participants seem to behave more in line with their personal goals in the personal identity condition. This summary shows that it is hard to deduce clear cut predictions for individuals with salient personal identity from SCT and SIDE, unless one knows their personal goals. This is not surprising, as SCT mainly focuses on social identity. Due to this, we focus on group members with salient social identity in Experiment 2, as has been done in various other studies on SIDE (e.g. Lea, Spears, \& de Groot, 2001; Postmes, Spears, \& Lea, 1998, 2001).

In the personal identity condition the RSC approach was supported as participants using CMC were more willing to violate the law than participants discussing FTF. However, in the social identity condition the results contradict the RSC approach, because the reversed effect of the personal identity condition occurred. At the same time, the results in the personal identity condition also contradict SIDE, because in the anonymous compared to the non-anonymous condition more instead of less adherence to the group norm was observed. These results are opposite to the pattern reported by Spears et al. (1990).

The reversed pattern of results for participants with salient social identity in Experiment 1 compared to the predictions of SIDE might have been caused by one of the two essential differences of the current compared to prior SIDE research. These differences are (a) the lack of a given group norm and (b) the manipulation of communication media instead of varying visual anonymity in the present research. As mentioned above, anonymity (or the lack of social context cues) is considered as one of the most striking differences between CMC and FTF. Additionally, Waldzus and Schubert (2000, Experiments 1-3) also found a reversed pattern of results compared to SIDE's prediction in their studies with a manipulation of visual anonymity. In these studies the participants were not informed about the norm of a superordinate category either. Thus, it seems more likely that the crucial differing characteristic of our Experiment 1 is the absence of a reference norm.

\section{The Impact of Category Norms on Attitude Change}

Earlier studies on SIDE showed that when a category norm was given, group members behaved in line with this norm as long as the salience of social identity was not undermined in a non-anonymous condition (e.g. Lea \& Spears, 1991; Postmes et al., 1998; Spears et al., 1990). As reported above, Waldzus and Schubert (2000, Experiment 4) found that the fit between the prototype of the local group and the norm of the superordinate category is a necessary precondition for the predicted effect of anonymity on conformity to the norm pertaining to the superordinate category. From this finding the authors conclude that the process of inferring the group norm from the information that is available (norm induction) is the crucial mediating cognitive process within SIDE.

The perceived norm might differ depending on whether interaction within the local groups is given (as in our Experiment 1 and earlier research on SIDE) or not (as in Waldzus \& Schubert's Experiment 4). Under which condition is the interacting small group a meaningful social entity to its members? It is very unlikely that the feeling of a common local group emerges solely from reading statements of other persons once. However, in an ongoing interaction one might increasingly feel like a 
member of the interacting group. Thus, in a setting where the reference norm of a superordinate social category is given to the interacting small group, both the superordinate social category and the interacting small group can be sources of social influence and attitude change. We assume that anonymity does not only moderate the influence of the norm of the superordinate social category as predicted by SIDE (more influence in the anonymous than in the non-anonymous conditions), but also the effect of the interacting small group and its members. The interacting group may be less relevant in anonymous communication than in non-anonymous communication, because an interacting small group (without past and future) only becomes meaningful when one has formed an impression about this group and its members. In anonymous communication as given in CMC, impression formation is much harder and takes longer than in FTF communication (Walther, 1992). A meaningless group does not provide the basis for social identification (Simon, Hastedt, \& Aufderheide, 1997), whereas a small group that becomes a subjectively important subcategory within the superordinate group can be a source of influence.

Which pattern of attitude change results from the influence of the interacting small group and the superordinate social category depending on anonymity and the knowledge about a norm of the social category? The more salient the superordinate social category, the more attitude change toward a category norm is expected when the norm is socially shared (e.g. explicitly given as reference norm). When the norm is not socially shared inconsistent or no attitude change at all should result. This should be the case even when a strong social categorization exists, because adherence to perceived norms that differ between participants of a study do not result in a consistent pattern of attitude change. Thus, in anonymous groups compared to non-anonymous groups more attitude change toward a socially shared category norm should result from the superordinate category. Without a socially shared norm, no (consistent) effect of anonymity can be predicted.
The impact of the interacting small group, which is stronger in the non-anonymous than in the anonymous condition, will also depend on the existence of a socially shared norm of the superordinate social category. In general, intragroup influence will lead to attitude change toward the group prototype which, in most cases, resembles a shift toward the direction that is dominant in the group prior to discussion (Turner, 1991). When a reference norm is given, this norm might act as an attribute of the superordinate category from which the small group distances itself (e.g. in the experiment of Spears et al., 1990 the attitude held by first year psychology students of the preceding year compared to the attitude of the small group members). Therefore, giving a reference norm can affect the prototype of the small group (i.e. the norm of the small group) similarly to outgroup attitudes and the prototype should shift toward the opposite pole of the scale (Hogg, Turner, \& Davidson, 1990). Attitudes will shift away from the norm of the superordinate category. ${ }^{5}$ In other words: when the norm of the superordinate category is imposed, non-anonymous group members create a local group identity based on their interpersonal bonds which they can explicitly contrast with the superordinate category and its norm-hence the interacting small group initiates a tendency to depolarize. When there is no explicit reference norm, however, the differentiation process in the interacting group has no clear anchor to work against. For this reason, prototype-based social influence will lead to polarization (i.e. an attitude change in the direction of the mean individual decision made before the discussion).

Taken together, we assume that two processes underlie the attitude change in small groups. The first is described by SIDE and is based on the adherence to the norm of a social category that is superordinate to the interacting group and shared by all group members. The second is the process of adherence to the small group norm (i.e. its prototype) which is based on norm induction. The first one is stronger when anonymity fosters the salience of the superordinate category, whereas the second one is 
stronger when non-anonymous interactions allow group members to form a meaningful small group. Postmes and Spears (2000) report findings that fit our predictions. They found that social influence in groups based on a common identity was stronger when they were anonymous (compared to non-anonymous groups), whereas social influence in groups that are based on interpersonal bonds was stronger when they were non-anonymous.

Based on this line of argumentation we predict more attitude change toward a given reference norm in anonymous groups than in non-anonymous groups. The attitude change in the non-anonymous condition with a given reference norm might even be directed away from the norm because the interacting group distances itself from the category norm. If no reference norm is given, the attitude change in the non-anonymous condition should be greater than in the anonymous condition when the influence of the local group is stronger than the influence of the social category. ${ }^{6}$ The attitude change will be directed toward the prototype of the local group. When the reference norm fits the norm within the sample (as in our Experiment 2) the attitude change will also be directed toward this norm even without giving a reference norm, because the attitudes of the group members before the discussion (and therefore also the group prototype) are most likely in line with the norm. The group discussion will amplify this tendency. These predictions on the one hand correspond to the results of earlier research on SIDE (with a given norm) and on the other hand correspond to those of Waldzus and Schubert (2000, Experiments 1-3) and Experiment 1 (without a given norm). Experiment 2 tested these hypotheses.

\section{Experiment 2}

In the following experiment participants either received or did not receive information about the norm of their common superordinate social category. Additionally, anonymity was varied during CMC within groups of three. Instead of a manipulation of communication media a manipulation of visual anonymity was chosen, because this experiment sought to test the impact of a given group norm in the context of SIDE. The impact of giving a group norm should generalize to the comparison of different communication media.

\section{Method}

Design and participants An experiment with a 2 (anonymity: anonymous vs. non-anonymous) $\times 2$ (reference norm: given vs. not given) design was conducted. Participants were 81 students (23 male, 58 female) of the University of Göttingen with a mean age of 23 years. Participants were recruited during lectures and from a dining hall and received DM 10 (about $€ 5)$ for participation. Five participants were excluded from further analysis because of a studentized deleted residual greater than 2.65 $(\alpha<.01)$ in multiple criteria outlier analysis (Neter, Kutner, Nachtschiem, \& Wasserman, 1996).

\section{Procedure and experimental manipulations} The experimental procedure was similar to Experiment 1. Directly upon arrival, participants in the anonymous condition were led to three different rooms equipped with computers, whereas participants in the non-anonymous condition were led to one room equipped with three computers. All questions and instructions were presented on the computer screen. The participants in the nonanonymous condition were not allowed to talk to one another. This manipulation of anonymity was successfully applied by Spears et al. (1990).

First, the participants had to indicate their opinion about two dilemmas, taken from a German version (Witte, 1971) of the choice dilemma questionnaire (Kogan \& Wallach, 1964):

25 years old Mrs. B. has a large scar close above her left eye. This scar disfigures her face and causes her a great deal of distress. Mrs. B. has the option of plastic surgery. However, with this intervention Mrs. B. would run the risk of losing her sight in her left eye.

After an injury to his spine Mr. G. now has to spend his whole life in bed. His physician suggests 
surgery that might improve his physical state. This surgery is not always successful. When it fails there is a high risk of fatality.

Participants were asked to decide at which level of chance for healing they would give the advice to decide in favor of the respective operations. These tasks were chosen to avoid the fulfillment of personal needs from the attitude indicated as in Experiment 1. Therefore, the decision task was more comparable to the task employed in earlier studies on SIDE.

Having read these dilemmas, the vantage of group decisions in extreme situations like illness was stated as a reason for the group discussion that followed. Moreover, the participants were informed that the other group members were also students of the University of Göttingen. Both statements were made in order to reinforce participants' social identity. Participants in the reference norm given condition were additionally informed (ostensibly as a stimulation of the discussion) that students of their university in earlier studies tended to decide against the surgery. Exact means from pilot data for both items were reported. Before the discussion started, the CMC software was explained to the participants. The participants were asked to discuss each dilemma for about 15 minutes. After the discussion, the participants again had to indicate their opinion concerning the dilemma and to work on questionnaires presented on the screen. Finally, they were debriefed, thanked, and paid.

Dependent measures The main dependent measure attitude change was assessed as mean attitude shift on the two dilemma items toward the cautious pole of the scale. The pretest as well as the mean individual decisions before the discussion indicated a norm for cautious behavior. Hence, the score was computed in a way that higher values indicate a stronger attitude change toward the cautious norm.

Additionally, social identification with the interacting small group/the students of the University of Göttingen were assessed with four items each (e.g. 'I am glad to be a member of this group/a student of the University of Göttingen', $\alpha=.75 / .70$ ).
To check for the effect of the manipulations two items asked for the anonymity of the self and the group. As both items were significantly correlated $\left(r(75)=.79^{7} p=.001\right)$, the mean of both items was computed as a measure of anonymity. Two additional items measured the norm to be cautious within the interacting small group (e.g. 'From the very beginning there was a tendency in our group to meet a cautious decision.'). As these items were also highly correlated $(r(76)=.70, p=.001)$, they were averaged. Finally, one item was added to measure the perceived norm of the students of the University of Göttingen ('Most of the students of the University of Göttingen would, in both cases, have selected a high percentage and therefore a low level of risk as a precondition for an operation.'). All items had to be answered on a 6-point scale ranging from 1 for 'I do not agree' to 6 for 'I entirely agree'.

\section{Results}

Manipulation checks To check for the effects of the independent manipulations ANOVAs with anonymity and reference norm as factors were computed. Participants in the anonymous condition felt more anonymous $(M=3.63, S D=$ 1.14) than participants in the non-anonymous condition $(M=2.68, S D=1.34)(F(1,71)=$ $11.47, p=.001)$. Participants who received information about a reference norm of the superordinate social category gave an estimate of this norm that was more cautious and therefore more in line with the given norm $(M=$ 4.37, $S D=1.24)$ than participants who were not informed $(M=3.81, S D=1.20)(F(1,68)=4.01$, $p=.049)$. The perceived norm of the interacting small group was not affected by the manipulation of the reference norm $(F(1,72)=$ $0.27)$.

The identification with the local group $(M=$ $3.73, S D=0.89)$ and with the university $(M=$ $4.04, S D=0.86)$ were both significantly above the midpoint of the scale $(t \mathrm{~s}>2.25, p \mathrm{~s}<.03)$. Therefore, it seems reasonable to assume that participants identified both with the local group and with their university. Taken together, the experimental manipulations were successful. 
Attitude change It was predicted that the attitude change toward the group norm would be stronger in the anonymous than in the nonanonymous condition when a reference norm of the superordinate social category was given (higher scores in the anonymous than in the non-anonymous condition). Conversely, the attitude change should be less strong in the anonymous condition when participants were not informed about the reference norm (lower scores in the anonymous than in the nonanonymous condition). To test this prediction a 2 (anonymity) $\times 2$ (reference norm) ANCOVA with mean attitude prior to discussion as a covariate and attitude change toward the group norm as the dependent measure was computed. The attitude prior to discussion was a reliable predictor for the attitude change $(F(1,71)=28.11, p<.001)$. Moreover, there was a main effect of the reference norm $(F(1,71)=6.63, p=.012)$. Although, the category norm was perceived as more cautious when the reference norm was given, the attitude change toward a cautious decision was lower for participants who were informed about a group norm $(M=-4.40, S E=1.96)$ than for participants who were not informed about this norm $(M=2.55, S E=1.85)$. This main effect was qualified by the predicted anonymity $\times$ reference norm interaction $(F(1,71)=5.90$, $p=.018$ ) (see Table 2). Participants who received a reference norm showed an attitude change away from the group norm in the nonanonymous condition $(M=-8.04, S E=2.88)$ that was greater than in the anonymous condition $(M=-0.75, S E=2.71)(F(1,71)=3.34, p$ $=.072)$. Conversely, participants who did not receive a reference norm showed slightly more attitude change toward the group norm in the non-anonymous $(M=5.58, S E=2.63)$ than in the anonymous condition $(M=-0.48, S E=$ 2.62) $(F(1,71)=2.65, p=.108){ }^{8}$

In additional analyses the manipulation check for perceived group norms was used to test the assumed processes. More precisely, partial correlations within the anonymous and the non-anonymous condition between attitude change and the students' norm as well as the norm of the interacting group controlled for the norm manipulation and the attitude prior to discussion were computed. This was done to test the assumption that the interacting group has more impact in the non-anonymous condition than in the anonymous conditions and the social category has more influence in the anonymous than in the non-anonymous condition. As predicted, in the non-anonymous condition a partial correlation between the perceived norm of the local group and the attitude change was found $(p=.30, p=.041$, one-tailed), whereas this correlation was not found in the anonymous condition $(p=.08, p=.329$, onetailed). In a multiple regression the anonymity $\times$ local group norm interaction was a significant predictor of attitude change $(\beta=.24, p=$ $.016)$ indicating that the difference between the two partial correlations is reliable. Thus, as expected, anonymity moderates the influence of the local group on attitude change.

There was no evidence for a moderation of the impact of the social category on attitude change by anonymity. In both conditions the perceived category norm and the attitude change correlated similarly (anonymous: $p=$ .31 , non-anonymous: $p=.32$, both $p<.05$, one-tailed, partial correlation controlled for decision prior to discussion and norm manipulation). Thus, we did not find evidence for the

Table 2. Estimated marginal means and standard errors for attitude change within ANCOVA (anonymity $\times$ reference norm, covariate decision before discussion) $(N=76)$

\begin{tabular}{lccccc}
\hline & \multicolumn{2}{c}{ Non-anonymous } & & \multicolumn{2}{c}{ Anonymous } \\
\cline { 2 - 3 } \cline { 5 - 6 } & $M$ & $S E$ & & $M$ & $S E$ \\
\hline Reference norm given & -8.04 & 2.88 & & -0.75 & 2.71 \\
No reference norm given & 5.58 & 2.63 & -0.48 & 2.62 \\
\hline
\end{tabular}


mechanism proposed by SIDE: the impact of the social category was not stronger in the anonymous than in the non-anonymous condition.

\section{Discussion}

Experiment 2 was conducted to test the impact of informing the members of an interacting small group about the norm of a superordinate category before they discuss a topic within their small group. It was predicted that informed members of anonymous groups show a greater attitude change toward the group norm than informed members of non-anonymous groups, whereas the opposite pattern was expected for group members who did not receive any information about the group norm. The results confirmed this prediction. The overall interaction was statistically reliable and the simple main effects were close to the conventional level of significance.

Even though the predicted reference norm $x$ anonymity interaction occurred and the relative attitude change was perfectly in line with the predictions, it is somewhat unexpected that participants in the anonymity/reference norm given condition did not show any attitude change toward the group norm. When the attitude change was not computed as a shift toward the end point of the scale (as it is usually done in research on group polarization), which was given as verbal description of the norm of the superordinate social category, but as a shift toward the actual values that were additionally given as category norms, the effect of anonymity could also be found $(F(1,33)=7.93, p=.008)$. However, the parameter values differed. In the anonymous condition the attitude change was directed more toward the explicitly given norm $(M=10.00, S E=2.22)$ than in the non-anonymous condition $(M=0.77, S E=2.35)$. These results demonstrate that participants in the anonymous/reference norm given condition changed their attitude toward the group norm stated in the instruction. However, the values given were more influential than the general direction that was stated verbally. Additionally, in this analysis the simple main effect that failed to be significant in the analysis reported above is significant. This result provides additional support for our prediction.

The index applied in the above analysis only makes sense for the condition with reference norm, because in the condition without reference norm participants were not informed about this norm. Thus, attitude change in this condition was directed neither toward nor away from the numerical norm $(t(39)=.69)$. Further research should address the question of which concrete norm is inferred by group members when they are informed about the general direction of a group norm and/or the exact mean of the ingroup norm.

The hypothesis that the attitude change is directed away from the given reference norm in the non-anonymous condition was supported. Taken together, the results for those groups that were informed about the reference norm match the findings of earlier studies on SIDE, whereas the results in the conditions without reference norm coincide with the results of Experiment 1 and of Waldzus and Schubert (2000, Experiments 1-3).

Finally, Experiment 2 provided initial evidence for the assumed underlying processes. The impact of the interacting group and its norm was found to be higher in the nonanonymous condition than in the anonymous condition. At the same time, we did not find evidence for the process suggested by SIDE. The impact of the superordinate social category was not stronger in the anonymous than in the non-anonymous condition but present in both conditions. One possible reason for this lack of evidence is the measure that was employed in this study: the perceived norm. SIDE does not suggest a change in influence of the group norm but a difference in salience of the social categorization. The latter has been found to mediate the impact of anonymity in a context where group norms were primed (Postmes et al., 2001). Thus, there is evidence for this aspect of the process not from the current, but from earlier research. However, it should also be noted that Lea et al. (2001) argued that categorizing oneself in terms of the interacting group is fostered by anonymity and thus they suggest that SIDE 
effects are based on the interacting group. This assumption is contradicted by the current findings in which anonymity leads to less attitude change driven by the small group norm.

\section{General discussion}

The aim of the present paper was to examine the explanation offered by SIDE for the inconsistent findings from research comparing attitude change in FTF and CMC. SIDE would predict that the differing degree of anonymity comparing both communication conditions will interact with the salient level of categorization in its impact on attitude change. If the experimental setting initiates a salient personal identity, higher attitude change in nonanonymous FTF communication is expected, whereas a setting that initiates a salient social identity will lead to higher attitude change in CMC. To test the validity of this explanation two assumptions had to be tested:

- Varying visual anonymity as well as implementing a broader manipulation of anonymity, namely the comparison of FTF and anonymous CMC, result in the effects predicted by SIDE.

- The knowledge about the norm of the social category moderates the effects predicted by SIDE.

Experiment 1 addressed the assumption that a broader manipulation of anonymity leads to the effects predicted by SIDE. The results confirmed this prediction at least partly when personal identity is salient. After a computermediated discussion participants with salient personal identity behaved more in line with personal goals and needs in terms of the attitude they expressed than participants after a FTF discussion. At the same time, they did not distance themselves from the group norm as one could also predict based on SCT. When social identity was salient greater attitude change after FTF communication compared to CMC was found. This unexpected pattern of results does not necessarily question the relevance of SIDE for the explanation of behavioral differences between groups communicating FTF and computer-mediated if one takes into account the results of Experiment 2.

Experiment 2 was conducted to test whether there is an impact of imposing a reference norm for a superordinate category. The findings of Experiment 2 indicate that informing participants explicitly about a reference norm moderates the effect of anonymity on attitude change. When the category norm was explicitly given, the effect of anonymity was in line with the prediction of SIDE, whereas it was reversed when no category norm was given. Thus, information about a reference norm is a crucial factor for the influence of a discussion on group members' attitudes. In sum, the effects of category norms are twofold: on the one hand, attitude change guided by the membership in a social category can only occur when knowledge about the group norm is socially shared. Therefore, a socially shared group norm is mandatory for self-categorization based attitude change. On the other hand, when the salience of the superordinate social category is undermined, as is the case in non-anonymous interacting small groups, the meaning of the category norm changes. Nonanonymous interacting small groups can distance themselves from the superordinate category and its norm and thus depolarize.

The current findings fit the pattern of attitude change predicted based on the two processes described above. However, the research reported here provides only little evidence for the assumed processes themselves. Only the moderation of the correlation between the norm of the local group and attitude change by anonymity points to the fact that the local group becomes more important when anonymity is low. Hence, both processes and their interplay have to be studied. Further research should specifically address the process of norm induction as suggested by Waldzus and Schubert (2000) to obtain a clearer picture of the cognitive processes that underlie the respective type of attitude change.

Following this reasoning, in a situation where several members of a social category interact, anonymity does not only moderate the salience 
of the superordinate social category as stated by SIDE, but also the impact of the interacting small group on their members' attitudes. Anonymity enhances the salience of the social category, whereas it undermines the impact of the interacting small group. Both processes might have been at work in studies on SIDE that used a paradigm including both types of groups (Postmes, Spears, \& Lea, 2002; Spears et al., 1990). An increasing level of anonymity fosters the conformity to the norm of the superordinate category and hinders the intragroup dynamic that would lead to an attitude change away from the category norm.

This conclusion does not question the main assumptions of SIDE, as there is also research supporting the predictions of SIDE in which only one level of categorization was present (Postmes et al., 1998; Sassenberg, 2000) and in which no category norm was given (Wilder, 1990). However, the effect of anonymity on the impact of the interacting small group has been underestimated and thus received insufficient attention until now. Exceptions are the work by Postmes and Spears (2000) who compared groups having strong interpersonal bonds with groups whose members share a common identity, and also the work by Sassenberg and Postmes (2002) who addressed the effect of anonymity on intragroup dynamics.

The assumption that a broader manipulation of anonymity, such as manipulating the communication media, results in the same pattern of attitude change as a manipulation of visual anonymity used in earlier studies on SIDE was not supported by the results of Experiment 1 in the salient social identity conditions. However, in this study no reference norm was given and the results in Experiment 1 parallel the results of Experiment 2 for groups that did not receive any information about the category norm. Thus, the effect of communication media (FTF versus CMC) does not differ from the effect of anonymity. The inconsistent results from research on media comparison can be explained based on SIDE when the effect of anonymity on intragroup processes is taken into account. In studies with a social context that fosters the salience of personal identity atti- tudes are supposed to be more strongly oriented toward individual goals in the anonymous condition. This might lead to less attitude change in CMC groups than in groups discussing FTF when personal goals are not related to the content of the discussed topic. In studies that foster the salience of social identity and suggest an ingroup norm, attitude change is supposed to be more strongly oriented toward this norm in the anonymous condition. When no norm is given attitude change is supposed to be stronger when anonymity is low.

Taken together, the results suggest that high anonymity (compared to low anonymity) as well as CMC (compared to FTF communication) cause more conformity to individual needs or goals when personal identity is salient. Higher conformity to a socially shared superordinate category norm is the result when social identity is salient. In the case of a socially shared category norm being absent, attitude change is directed toward the norm of the local group. This intragroup influence is stronger when anonymity is low.

\section{Notes}

1. One might object that the publicity in FTF communication and in a non-anonymous condition leads to more conformity toward the group norm when social identity is salient. However, following SCT the adherence to group norms is not a result of public compliance but an outcome of perceiving oneself as a group member and thus, considering the group norm as the way one wants to be. In line with this assumption Noel, Wann, and Branscombe (1995) have found that group members show the same amount of conformity to ingroup norms no matter whether they state their attitudes publicly or privately except when they became a member of the group very recently. Moreover, there is evidence for strong conformity toward group norms in CMC that is based on social identification with the ingroup (e.g. Sassenberg, 2002).

2. Participants in the FTF and the GMC condition were informed that their behavior was recorded. This might affect the anonymity of the self, whereas it does not affect the anonymity of the group (i.e. the amount of information a 
participant has about his/her group members), which is the crucial variable within the cognitive aspect of SIDE addressed here (see Spears \& Lea, 1994 , for an extensive discussion of the differing effects of the anonymity of the self and the anonymity of the group). Thus, informing the participants about the recording of their behavior, which is necessary for ethical reasons, should not affect the results.

3. This calculation follows the procedure applied by Spears et al. (1990) and thus ensures the comparability of the results. In reference to Campbell and Stanley (1963) the authors argued that with this procedure, even with randomized assignment of the participants to the conditions, the remaining error variance in the analysis should be controlled.

4. The personal identity condition can also be seen as an intergroup context made up by the different majors of the group members (we wish to thank Martin Lea for this alternative interpretation). In this case an attitude shift in the predominant direction can be interpreted as a stronger conformity toward the group norm that is inferred from the individual's attitude via self-anchoring (Cadinu \& Rothbart, 1996). However, in this study it does not matter if differences between group members were established based on interindividual differences or intergroup differences within the interacting group. The important fact is that the social identity of the small group was salient in one and not salient in the other condition.

5. This would also explain why in the non-anonymous / social identity condition in Spears et al.'s (1990) experiment a slight attitude change away from the reference norm occurred and not a shift toward the reference norm as expected from SCT.

6. The strength of the influence of the local group and the social category can be determined by several factors such as the salience of the respective level of categorization and the social identification with the group.

7. Due to technical problems some questionnaire data from four participants are missing.

8. Maxwell and Delaney (1990, p. 145) suggest that $F$ tests for factors with two levels can be computed one-tailed. Hence, reporting two-tailed tests in our case is very conservative given that our hypothesis was directed. A less conservative onetailed test reveals that one $p$ reaches the conventional level of statistical significance and the other one is very close to if $(p=.054)$.

\section{Acknowledgments}

We are grateful to Kai J. Jonas, Thomas Kessler, Martin Lea, Russell Spears, Thomas Schubert, Sven Waldzus, and K. Andrew Woltin for their extensive and valuable comments on an earlier version of this article. We also extend our appreciation to Hazel Willis for help with manuscript preparation and Melanie Appel, Lars Gargulla, and Kai Heutelbeck for their assistance in data collection.

\section{References}

Cadinu, M. R., \& Rothbart, M. (1996). Selfanchoring and differentiation processes in the minimal group setting. Journal of Personality and Social Psychology, 70, 661-677.

Campbell, D. T., \& Stanley, J. C. (1963). Experimental and quasi-experimental designs for research. Chicago: Rand-McNally.

Diener, E. (1980). Deindividuation: The absence of self-awareness and self-regulation in group members. In P. B. Paulus (Ed.), The psychology of group influence (pp. 209-242). Hillsdale, NJ: Erlbaum.

Festinger, L., Pepitone, A., \& Newcomb, T. (1952). Some consequences of de-individuation in a group. Journal of Abnormal and Social Psychology, 47, 382-389.

Goethals, G. R. \& Zanna, M. P. (1979). The role of social comparison in choice shifts. Journal of Personality and Social Psychology, 37, 1469-1476.

Hinder, E. (1987). Grundlagenprobleme bei der Messung des sozial-moralischen Urteils [Basic problems in the measurement of moral judgement]. Frankfurt: Lang.

Hogg, M. A., Turner, J. C., \& Davidson, B. (1990). Polarized norms and social frames of reference: A test of the self-categorization theory of group polarization. Basic and Applied Social Psychology, 11, 77-100.

Kiesler, S., Siegel, J., \& McGuire, T. W. (1984). Social psychological aspects of computer-mediated communication. American Psychologist, 39, 1123-1134.

Kiesler, S., \& Sproull, L. (1992). Group decision making and communication technology. Organizational Behavior and Human Decision Processes, 52, 96-123.

Kogan, N., \& Wallach, M. A. (1964). Risk taking: A study in cognition and personality. New York: Holt.

Lea, M., \& Spears, R. (1991). Computer-mediated communication, de-individuation and group 
decision making. International Journal of ManMachine Studies, 39, 283-301.

Lea, M., Spears, R., \& de Groot, D. (2001). Knowing me, knowing you: Anonymity effects on social identity processes within groups. Personality and Social Psychology Bulletin, 27, 526-537.

Matheson, K., \& Zanna, M. P. (1988). The impact of computer-mediated communication on selfawareness. Computers in Human Behavior, 4, 221-233.

Matheson, K., \& Zanna, M. P. (1989). Persuasion as a function of self-awareness in computer-mediated communication. Social Behaviour, 4, 99-111.

Maxwell, S. E., \& Delaney, H. D. (1990). Designing experiments and analyzing data. Pacific Grove, CA: Brooks/Cole.

McGuire, T. W., Kiesler, S., \& Siegel, J. (1987). Group and computer-mediated discussion effects in risk decision making. Journal of Personality and Social Psychology, 52, 917-930.

McKenna, K., \& Bargh, J.A. (2000). Plan 9 from Cyberspace: The implications of the Internet for personality and social psychology. Personality and Social Psychology Review, 4, 57-75.

Neter, J., Kutner, M. H., Nachtschiem, C.J., \& Wasserman, W. (1996). Applied linear statistical models (4th ed.). Boston: McGraw-Hill.

Noel, J. G., Wann, D. L., \& Branscombe, N. R. (1995). Peripheral ingroup membership status and public negativity toward outgroups. Journal of Personality and Social Psychology, 68, 127-137.

Postmes, T., \& Spears, R., (1997). Quality of decisions, group norms and social identity: Biased information sampling or sampled biases. Paper presented at the 5th Münster Workshop on the Social Identity Approach, Rothenberge, Germany.

Postmes, T., \& Spears, R., (1998). Deindividuation and antinormative behavior: A meta-analysis. Psychological Bulletin, 123, 238-259.

Postmes, T., \& Spears, R., (2000). Refining the cognitive redefinition of the group:

Deindividuation effects in common bond vs. common identity groups. In T. Postmes, R. Spears, M. Lea, \& S. Reicher (Eds.), SIDE effects centre stage: Recent developments in studies of deindividuation in groups (pp. 63-78). Amsterdam: KNAW.

Postmes, T., Spears, R., \& Lea, M. (1998). Breaching or building social boundaries? SIDE-effects of computer-mediated communication. Communication Research, 25, 689-715.

Postmes, T., Spears, R., \& Lea, M. (1999). Social identification, normative content, and 'deindividuation' in computer-mediated groups.
In N. Ellemers, R. Spears, \& B. Doosje (Eds.), Social identity (pp. 164-183). Oxford: Blackwell.

Postmes, T., Spears, R., \& Lea, M. (2002). The effects of anonymity in intergroup discussions: Bipolarization in computer-mediated groups. Group Dynamics: Theory, Research and Practice, 6, 3-16.

Postmes, T., Spears, R., Lea, M., \& Reicher, S. (Eds.) (2000). SIDE effects centre stage: Recent developments in studies of de-individuation in groups. Amsterdam: KNAW.

Postmes, T., Spears, R., Sakhel, K., \& de Groot, D. (2001). Social influence in computer-mediated groups: The effects of anonymity on group behavior. Personality and Social Psychology Bulletin, 27, 1243-1254.

Reicher, S. D. (1984). Social influence in the crowd: Attitudinal and behavioural effects of deindividuation in conditions of high and low group salience. British Journal of Social Psychology, 23, 341-350.

Reicher, S. D. (1987). Crowd behavior as social action. In J. C. Turner, M. A. Hogg, P. J. Oakes, S. D. Reicher, \& M. S. Wetherell (Eds.), Rediscovering the social group. A self-categorization theory (pp. 171-202). New York: Basil Blackwell.

Reicher, S. D., Spears, R., \& Postmes, T. (1995). A social identity model of deindividuation phenomena. In W. Stroebe \& M. Hewstone (Eds.), European Review of Social Psychology (Vol. 6, pp. 161-198). Chichester, UK: Wiley.

Sassenberg, K. (2000). The two faces of anonymity: Effects on group decision making. In T. Postmes, R. Spears, M. Lea, \& S. Reicher (Eds.), SIDE issues centre stage: Recent developments in studies of deindividuation in groups (pp. 93-106). Amsterdam: KNAW.

Sassenberg, K. (2002). Common bond and common identity groups on the Internet: Attachment and normative behavior in on-topic and off-topic chats. Group Dynamics: Theory, Research, and Practice, 6, 27-37.

Sassenberg, K., \& Postmes, T. (2002). Cognitive and strategic processes in small groups: Effects of anonymity of the self and anonymity of the group on social influence. British Journal of Social Psychology, 41, 463-480.

Sassenberg, K., Rabung, S., \& Boos, M. (1999). Selbstaufmerksamkeit in der computervermittelten Kommunikation [Selfawareness in computer-mediated communication]. In U.-D. Reips, B. Batinic, W. Bandilla, M. Bosnjak, L. Gräf, K. Moser et al. (Eds.), Aktuelle Online Forschung-Trends, Techniken, Ergebnisse. [Current 
internet science-trends, techniques, results].

Zurich: Online Press. [Retrieved September 15 2002 from the World Wide Web]. Available URL: http: //dgof.de/tband99/.

Siegel, J., Dubrovsky, V., Kiesler, S., \& McGuire, T. W. (1986). Group processes in computer-mediated communication. Organizational Behavior and Human Decision Processes, 37, 157-187.

Simon, B., Hastedt, C., \& Aufderheide, B. (1997). When self-categorization makes sense: The role of meaningful social categorization in minority and majority members' self-perception. Journal of Personality and Social Psychology, 73, 310-320.

Spears, R., \& Lea, M. (1992). Social influence and the influence of the 'social' in computer-mediated communication. In M. Lea (Ed.), Contexts of computer-mediated communication (pp. 30-65). New York: Harvester Wheatsheaf.

Spears, R., \& Lea, M. (1994). Panacea or panopticum? The hidden power of computermediated communication. Communication Research, 21, 427-459.

Spears, R., Lea, M., \& Lee, S. (1990). Deindividuation and group polarization in computermediated communication. British Journal of Social Psychology, 29, 121-134.

Tajfel, H., \& Turner, J. C. (1979). An integrative theory of intergroup conflict. In W. G. Austin \& S. Worchel (Eds.), The social psychology of intergroup relations (pp. 33-47). Monterey, CA: Brooks/Cole.

Turner, J. C. (1991). Social influence. Milton Keynes, UK: Open University Press.

Turner, J. C., Hogg, M. A., Oakes, P. J., Reicher, S. D., \& Wetherell, M. S. (Eds.). (1987). Rediscovering the social group. A self-categorization theory. New York: Basil Blackwell.

Vinokur, A., \& Burnstein, E. (1974). Effects of partially shared persuasive arguments on groupinduced shifts. Journal of Personality and Social Psychology, 29, 305-315.

Waldzus, S., \& Schubert, T. (2000). Group norm and category norm in anonymous situations: Two sources of social influence. In T. Postmes, R. Spears, M. Lea, \& S. Reicher (Eds.), SIDE effects centre stage: Recent developments in studies of deindividuation in groups (pp. 31-46). Amsterdam: KNAW.
Walther, J. B. (1992). Interpersonal effects in computer-mediated interaction. Communication Research, 19, 52-90.

Weisband, S. P. (1992). Group decision and first advocacy effects in computer-mediated and face-to-face decision making groups. Organizational Behavior and Human Decision Process, 53, 352-380.

Wetherell, M. S. (1987). Social identity and group polarization. In J. C. Turner, M. A. Hogg, P. J. Oakes, S. D. Reicher, \& M. S. Wetherell (Eds.), Rediscovering the social group. A self-categorization theory (pp. 142-170). New York: Basil Blackwell.

Wilder, D. A. (1990). Some determinants of the persuasive power of in-group and out-group: Organization of information and attribution of interdependence. Journal of Personality and Social Psychology, 59, 1202-1213.

Witte, E. H. (1971). Das 'risky-shift'-Phänomen: Eine kritische Untersuchung der bestehenden Hypothesen [The 'risky shift' phenomenon: A critical survey of the existing hypotheses]. Psychologie und Praxis, 15, 104-117.

Paper received 7 February 2002; revised version accepted 2 January 2003.

\section{Biographical notes}

KAI SASSENBERG is an assistant professor at the Department of Social Psychology at FriedrichSchiller University of Jena (Germany). He received his PhD from the Georg-August University of Göttingen (Germany). His current research interests include social discrimination, selfregulation in intergroup behavior, and group norms.

MARGARETE BOOS is a professor in the Department of Psychology at Georg-August University of Göttingen (Germany). She received her $\mathrm{PhD}$ from the Friedrich-Wilhelms University of Bonn (Germany). Her current research interests include computer-mediated communication, group problem solving, group decision making, and coherence in dialogues. 